\title{
A Novel Proposal for a Cloud-Based Distance Education Model
}

\author{
Awatef Balobaid, Debatosh Debnath \\ Department of Computer Science and Engineering, Oakland University, USA
}

\begin{abstract}
Advancements in technology, especially the availability of the Internet, have brought a revolutionary change in the education sector, increasing the scope of online education worldwide. Today distance education is vastly dependent on elearning portals. In addition, the cloud and virtualization technology have gained popularity. Many universities providing distance education are moving away from physical infrastructure to cloud computing due to its features and advantages. Cloud-based e-learning and distance education platforms are cost effective in comparison with other services. The aim of this paper is to propose a new cloud-based distance education model: Distance Education as a Service (DEaaS). Moreover, this paper aims to discuss how underprivileged students and children from underdeveloped countries can benefit from cloud-based distance education.
\end{abstract}

\section{Introduction}

In today's global world, the Internet facilitate educational content delivery in a major fashion. The Internet has removed many obstacles related to language or geography and has expedited growth and established an international education community. The environment of education has been influenced by the rapid development of Information Communication Technology (ICT). Cloud computing is the latest trend in the world of technology that can provides a tremendous potential in distance learning. It has successfully expanded online education in the environment of learning and also provided opportunities for exploring new horizons [1]. The best way to get the most benefits from e-learning is by carefully implementing and designing the cloud environment of e-learning. Elearning facilitates an environment of collaborative learning for students, increasing their motivation and engagement in addition to allowing them to become independent and self-directed learners.

Distance learning can help improve education quality and help hone developing learners' skills, which in turn will help learners advance their socioeconomic status. Just as the cloud has provided businesses with the computing power they need to grow their infrastructure regarding network, storage hardware and platform, its innovations can benefit educational institutions and learners alike.

Cloud computing can be described as a platform on which different kinds of applications and services are provided over the Internet and is referred to as the cloud. Educational institutions benefit from cloud computing in a significant way. The cloud provides dynamic learning on niche technologies, reduces management overhead, eliminates capital expenditure, provides access to pragmatic learning and reduces operational expenditures [1, 14]. Already there are several e-learning models and elearning cloud models. Today universities are providing distance education services to students using e-learning platforms [2]. The aim of this paper is to develop a new distance education cloud framework: Distance Education as a Cloud (DEaaS). This paper analyzes scalability and flexibility of cloud computing in the field of education and describes the challenges related to it.

The first part of this paper provides a description of the development of distance learning, e-learning and cloud based distance learning and provides insights into service and deployment models of the cloud. Another section of this part of the paper provides an overview of the advantages and disadvantage of cloud computing in the field of distance education. The second part of this paper discusses studies on e-learning and cloud-based education service models, approaches, etc. It also describes how traditional educational models are shifting to the cloud and examines best practices in transitioning between the traditional and current cloud- based distance learning models. The third part of this paper provides an explanation of the proposed framework for the education cloud, which facilitates distance education as a service through the education cloud. The fourth part focuses on some research findings and suggestions for future work based on this proposed model.

\section{Distance Learning}

Distance learning initially started back in 1999 at a CBY Systems seminar that was held in Los Angeles. In their research, Simões et al. [3] mentioned that the main aim of the seminar was the use of IT developments to enhance learning mainly through distributed and standalone environments [4]. The main technologies that were developed to enhance learning include the following [5]:

- Content Management systems (CMS)

- Learning Content Management Systems (LCMS)

- Personal Learning Management Systems (PLE)

Distance learning has become highly popular over the last few years. Consequently, it is important 
to ensure that the services are effectively provided. Development of distance learning involved taking advantage of the cloud. Cloud computing has proved to be highly beneficial in distance learning, especially when it comes to the delivery of learning material. There are several benefits associated with distance learning. The main benefit is that the students have the ability to conduct the usual day to day chores or work. With distance learning, the students do not have to relocate in order to learn. They can gain quality education at the comfort of their home. This is one of the major reasons why distance learning has gained popularity over the years.

While some worry that distance learning reduces students' access to educational support, leaving the students learning alone, this is not has been the case. In distance education, students will have tutors, alumni associations, network support, online conferencing and several other learning support systems. All these services are available to all students regardless of their location [1]. The most important part of studying online is the method of communication. Students are able to communicate with tutors, advisors, faculty, or university offices. This interaction mainly occurs via email, but is allowed conducted via real time web conferencing and chats. As mentioned above, students can study at home or at any other place they feel comfortable. In fact, many students tend to read the course material when travelling or on when on breaks from work. Since many students spend a lot of time travelling, they can take advantage of going through the course material online. Distance learning benefits both the student as well as the work place. Students have the ability to directly implement what is learned in their work.

\subsection{Advantages of Distance Learning}

Distance learning today can be considered virtual learning, where the students are at the core of an online school or an online branch of a traditional school. Some of the main advantages of distance learning are as follows [1]:

- A study plan: Students have the ability to create their own study plan to enable them to learn at their own pace without direct effect on their day to day lives.

- Innovation: Due to the nature of virtual schooling, quality teaching techniques can be easily implemented.

- Access to quality tutors: Unlike other institutions, programs in distance learning can be offered by the leading researchers in a specific field of study regardless of where they are located. This is an added advantage to the student and assures quality of education.
- Flexibility: With distance learning, students can choose a course consistent with their level of experience and qualifications.

- Visual learning environment: In a distance education system, the use of visual aids tends to be more effectively implemented to deliver effective training and learning experiences. Distance learning is all about visual learning due to its nature.

- Efficiency: With online learning, the student is able to learn at any place and any time. Ease of access to educational resources is another main advantage of distance learning. With advancements in distance learning, it is possible to provide more students with educational opportunities.

- Access to all ages: Distance learning is beneficial to all people, both young students as well as adults in continuing education programs. Adults can enroll in the online courses to develop and enhance their careers and ensure job security without interrupting their careers and family life.

- Affordability: Distance learning only requires a working Internet connection. This means that the student will be able to save on other costs involved with on-campus studies, such as transportation, time, and other additional living costs.

\subsection{Social Networking in Distance Learning}

The number of people keen to learn technology through social networking sites has increased significantly. Due to its global outreach, people from different regions and learning backgrounds can share their diversified knowledge, experiences, and opinions in an online setting. Things get more interesting when students respond to each other's work and collaborate for something new, innovative and inspiring. Not only do users get to know each other but also they get to hone teamwork, management, communication, and social skills. Online group mentors and educational experts check their work and provide feedback through the LMS's grading platform. Online training, exams, certifications, and degrees are of immense importance not only for skill development and career building but also to improve the learner's resume and educational profile. These skills are now accepted and appreciated worldwide for employment and promotion.

Online distance learning programs are now more responsive to the needs of learners. Their pedagogy is more scaffolded and the activities, quizzes, assignments, online discussions, projects, presentations, and tasks are primarily outcome based. Target oriented learning is more inspiring and selfmotivating. This method of distance learning has connected students around the globe to educational institutes. Its flexible study plans have made learning easier, more efficient, and more timely as well as 
made education more affordable for the learner and cost effective for the provider. Well planned educational curriculum and study modules attract the attention and develop the interests of students. Their pursuit of additional learning enhances engineering skills, develops problem-solving skills, improves conceptual understanding, facilitates professional resource building and provides excellent future career opportunities. Due to increased use of smartphones, tablets, digital diaries and handheld devices, different online learning approaches have been adapted for content knowledge creation, design, organization, planning, and delivery. These innovations include digital platform generic elearning modules, intelligently programmed educational portals and academically enriched digital contents. In this context, students are now using several online e-learning platforms. With improved quality content, easy to search and access, precisely articulated and improved usability for all available digital mediums, distance education has taken its place in the next generation online learning[22].

\subsection{Cloud-based Distance Learning}

In recent years, cloud computing has gained popularity for scalability, reliability and efficiency. The physical infrastructure for e-learning and Internet-based distance learning is expensive. Therefore, the cloud can be an effective solution that provides this complex service easily and more efficiently. But the importance of cloud-based distance learning is not limited to the cloud infrastructure; cloud-based content management and other issues are just as important. The cloud has the ability to provide on demand service. Moreover, there is innovation, ease of access and ease of creation. There are several advantages associated with combining online learning with cloud technology. Because of efficiency and scalability, cloud computing is now a needed for organizations [7]. Cloud-based distance learning is a promising alternative solution to physical storage. Some of the main advantages may include the following [3]:

- Scalability

- Efficiency

- Technological effectiveness

- Affordability

- User personalization

- Quality of service

- Optimization of resource allocation

- Maintenance free e-learning solutions

- Improved instructional quality

- Ease of management

Cloud Computing has ushered in a new age of learning, which leverages the cloud's e-Learning tools and the virtualization capabilities of the hardware. It diminishes the production and maintenance expenditure of learning resources. Right now, the arrangement of cloud computing technologies and e-learning has been barely walked around. There have been some pertinent efforts to utilize IaaS cloud technologies in education centers on the stipulation of virtual machines for students in a particular time [20].

An additional illustration of a tool that can be observed in a particular context is BlueSky, whose structural design has numerous features aimed at the proficient provision and administration of e-Learning services. It has the ability to schedule resources in advance, to sizzle contents and portals before they are essentially desired, to protect performance in synchronized access. Another tool, CloudIA, is a framework that offers on-demand establishment and VM image configuration so students can enjoy their own Java servlet environment for research and experimentation. It includes an Apache web server, PHP, Tomcat, and MySQL. Using this method, students can focus more on application development, deployment and testing in a servlet container. CloudIA enhances the learning experience, providing concept clarification and hands on experience with multiple server models. It clearly offers a rich amalgam of theory and practice, which is essential for e-learning in this digital age of globalization where online learning competes with or at complements traditional education. Other suggestions for private and virtual e-learning are related to services that depend on the cloud, like GoogleDocs or YouTube [20, 21].

\subsection{Security in Distance Education}

Modern Internet and digital technologies have provided numerous options-directs or indirect, synchronous or asynchronous, general or specific, public or private communication, and personal, group and collaborative study scenarios - that benefit traditional education, e-learning environments, and training sectors. These digital innovations also raise some serious concerns about privacy for students and educators alike. Students need to be concerned about their privacy and educational institutions and educators must anticipate and guard against profile and credential breaches, identity theft, blackmail, and related online data privacy and security issues.

Developers of digital learning portals, software, apps and communities; online education and training institutes and organizations; social media platforms directly or indirectly related to online education; online educational research and training channels; and forums and discussion groups should provide an assurance of privacy for certain forms of personal data[20].

Personal data may include but is not limited to Internet usage habits, the number of clicks on individual pages, social media profile, location, 
biometric identity, health, financial and legal information, habits and interests, likes and dislikes, friends and special ones, family background, sexual orientation, criminal history records, and disciplinary incidents.

This data can be misused or sold to companies for online behavioral research, it can be accessed for possible identity theft, blackmail, or life threats by criminals, psychopaths, and perverts. It also can be used to destroy people's reputations, social lives, or peace of mind.

Online privacy is always at risk while using unsecured TCP/IP connections; when using application layer protocols like HTTP, NNTP, POP3, and SMTP; when encountering hidden hyperlinks; while chatting online and surfing the web; when installing and updating from unknown sources; when accessing and registering websites; while using social media accounts; and when adding insecure third party add-ons to browsers. Additionally, personal data privacy is always at risk while enrolling in public, private or non-profit Massive Open Online Courses (MOOCs). It is potentially compromised when filling out online applications, when accessing online services, when connecting to social media platforms.

A well-organized plan is required to the overcome privacy issues discussed above. Collaboration and ongoing discussion is needed among programmers, educational experts, mentors, educational software development companies, trainers, research and educational institutes and organizations, data security engineers, protocol designers, data researchers, data security, privacy policy and law making corporations. There is a strong need to standardize policies regarding educational content creation, online implementation, secure sharing, and user access. Because users are growing each day, privacy issues are likewise growing. Every time students enroll or access information either through desktops, laptops or tablets at home or through a smartphone on the go, their privacy is at risk. Online law enforcement agencies should strictly enforce existing laws and advocate for better laws to protect users' privacy because without accountability, prevention is next to impossible. It is true that privacy measures should be taken as a first priority, so if someone wants to violate another's data security she or he will know the punishments for this behavior $[16,20]$.

Distance learners in online environments are expected to share their personal info with their educators and peers. It is therefore reasonable for them to expect that education providers and their affiliates will ensure that their online transactions are secure and that their personal data is protected.

\section{Literature Review}

Distance learning is still at a developmental stage and requires several advancements to create a better learning environment [8]. E-learning is described as being in the infancy stage. This means that it needs to grow and develop further to ensure quality and productivity. In many cases, dated e-learning solutions are still being used in various educational institutions. This is one of the problems faced by elearning development. Using traditional or outdated learning technologies is inadequate due to network developments like cloud computing and Rich Internet Applications [3]. Ideas created through the use and development of cloud-based distance learning methods can actually become technological solutions through the combination of older online learning methods with new cloud computing technology [3]. The migration of cloud technologies to the online learning sector is an effective way of creating an e-learning platform or solution in the cloud environment [10].

Some individuals like Wang et al. have introduced cloud based online learning to integrate different e-learning platforms [9]. This leads to enhanced interoperability of the learning material. Other authors like Rajam et al. propose the use of a distance learning computational cloud (usually abbreviated as eLC2) to manage various learning components [6]. The proposed method helps in the management of learning tasks and mainly comprises of the GUI, which renders presentations and exchange of messages among clients.

Cloud computing has been highly beneficial to distance learning users. Though there are several advantages brought to users through the paradigm, it is essential to develop cloud computing further so as to know how the e-learning platforms can be easily included in the cloud. Some of the main factors that should be considered when doing this include the composition of cloud computing and its architectural, deployment, and service models. Each of these factors should be considered independently. Due to these advantages, cloud computing positively impacts all organizations by simply lowering the total cost of ownership (abbreviated as TCO) by IT solutions [12, 13]. This in turn impacts business creation solutions, which in turn extend to macroeconomic performance in both national and global sectors.

All the advantages mentioned above apply to both public and private business sectors, including healthcare, e-learning and government activities [12]. Cloud computing has gained extensive popularity in both academic and industrial institutions. The main reasons behind this are the advantages associated with this paradigm: flexibility, affordability and ease of management. When used in education sectors, cloud computing is referred to as Education and 
Learning as a Service. The technology has made the top ten lists of strategic technologies compiled by the US analyst firm, Gartner [2]. It has been described as among the top ten strategic technologies for several consecutive years. It was initially listed as a Web Platform and Web Oriented Architecture back in 2008. The reason behind this was the success achieved in the Software as a Service model. This was later changed to cloud computing in 2009 [12, 15].

As a result of this series of technological innovations in education, a series of research reports and initiatives have been developed to track progress and to share research on how they technologies are influencing education. The Horizon reports, for example, were published as a result of collaboration among various organizations, which include the following [12]:

- NMC: New Media Consortium

- ELI: EDUCAUSE Learning Initiative

This is a program of EDUCAUSE, a non-profit organization that aims at providing an educational perspective on various developing technologies. It mainly dwells on K-12 education and higher education. This organization studies developing technologies that may impact the education system.

There is no large difference between K-12 and higher education when it comes to technology. The main difference is the intensity of use. The K-12 sector is a little bit behind in technology use when compared to the higher education system.

\section{Cloud Computing in Distance Education}

\subsection{How It Can Benefit Students}

This proposed work is not only limited to discussing the DEaaS model but also to examining how the DEaaS can help students from developing countries through cloud-based distance learning. A proper education system is one of the major challenges faced by many countries. One of the ways of addressing this issue is through distance learning.

As already mentioned, there are several benefits to opting for e-learning, which has led to its use in several countries, and its management via could computing. The traditional methods used to provide e-learning service may not help students in getting practical knowledge when they are taught with technology $[11,16]$.

Therefore, some of the main benefits or uses of cloud computing in developing countries are as follows:

- Material distribution: The whole essence of imposing distance learning is to be able to reach a large population of students. With the cloud computing platform, distribution of textbooks, modules and other education related materials are easier. Material delivery is one of the main advantages of cloud computing in education.

- Sharing of education materials: With the older elearning platforms, it is hard for students and teachers to share their educational material. Through social computing, which is a part of cloud computing, teachers and students will be able to share their educational data. They will be able to create learning groups to enhance education. This makes it easier for students in developing countries to research and find quality information.

- Integration of new education modes: Introducing new educational modes in developing countries is highly challenging because of the difficulty to reach a large group of students. With cloud computing, educational modes like corporate learning and industry based- learning programs are easier to access and integrate.

- Affordability: Using cloud computing in education is highly cost effective. The main reason behind this is that it does not require a heavy or complicated IT infrastructure. The basic infrastructure is enough for the distribution of material.

These are just some of the main uses and benefits of incorporating cloud computing in education. Though it is highly advisable for developing countries, some challenges may be encountered. One of the main challenges is cloud computing software. Though some cloud computing software and applications are available from the open source community, others are highly expensive [17].

\subsection{Distance Education Requires Changes to Existing Cloud}

When cloud computing is compared to traditional provisioning models, it stands out due to several advantages. Some of the main advantages associated with cloud computing include the following:

- Reduced capital: Cloud computing has a lower upfront cost in terms of required software and hardware. Apart from that, it also requires less professional staff who manage the servers and perform software upgrades.

- Faster: Cloud computing takes a shorter time to launch compared to traditional IT provisioning models. A function that could have taken the traditional methods days to perform is completed in hours using cloud computing.

- Performance: It has a higher level of performance.

- Scalability: It is easily scalable.

- Fault tolerance: Cloud computing has an amazing fault tolerance ability.

- Efficiency: Cloud computing has enhanced the compatibility of collaboration. This allows users to 
access information from almost any device. This leads to high accessibility and ease of movement.

To make distance education by cloud computing a more promising education model for developing countries, the following changes should be addressed at the service level:

- Virtualized learning resources should be highly flexible at the IaaS layer. The main reason behind this is to be able to provide resources to users who may include companies, schools and students.

- A group of modules should be created in the PaaS layer. The module sets should provide various learning components and other services.

- For each individual institution, component groups should be arrayed as cloud services to a self-oriented and innovative interface in the SaaS layer.

The remaining architecture component should be able to manage the learning platform instances in the cloud. This means that it should be improved to comprise new middleware layers. The middleware layer is specifically designed to manage the learning solutions in the cloud. In order to manage a set of platforms, the middleware layer has to communicate with the other architectural layers.

\section{Proposed Model DEaaS}

\subsection{Structure of Proposed Model}

The aim of education is to enlighten learners. Cloud-based distance-learning can help students from both rural and urban areas in developing countries in spite of differences in economic status, which in turn will reduce the knowledge difference among people. It will create a society based on knowledge and enhance the competitiveness of each nation. The proposed model will also provide digital library facilities for distance learning students.

The aim of this paper is to provide distance education services to geographically diverse and economically disadvantaged students. Cloud-based distance learning facilitates content development and anytime, anywhere learning. It is easy for teachers and students to use and to access.

Its solutions will be spread across but not limited to platforms like e-book, e-learning, mobile, and IPTV. Learners will be able to create their content using authoring tools or by sharing, reusing, or repurposing existing content. Various interaction applications like email, video conferencing and messaging and applications of social networking for collaboration can be integrated within the proposed cloud-based distance education model. In this proposed model, several applications are integrated, for example:

- Personal website - It will have links to student and teacher websites
- Interactive game and applications

- Video and picture sharing

- Social networks like Facebook

- E-learning and e-book

- Wikipedia

- Peer-to-peer application sharing

- Blog

- Collaborative tools like messaging and email

- Distance learning systems like video and voice conferencing

Using the DEaaS model, students will be able to exchange information and ideas or communicate among themselves to learn and create without wasting time, spending money, exhausting and expensive travel. Students will have the flexibility to learn any subject by registering and interacting within an e-classroom. They will have control over exercise and learn or revise themselves at their own pace. Tests will be provided to evaluate their understanding upon finishing each course. The following will be included within the proposed model:

- Database Service - The digital library will contain a large number of journals, reports and papers.

- It will house a collection of complete papers with images, including research studies and theses as well as host an interlibrary loan service.

- E-book directory

Though most institutions still use traditional methods of distance learning, cloud computing in education is still gaining popularity with both teachers and students. When using cloud computing in distance learning, the options available to students and teachers can be categorized into three main categories. The categories include:

1) Voice: These are audio based instructions. They may include audio conferencing and phone interactive technologies.

2) Video: This includes image slides and moving images like films. Real time films can be combined with audio conferencing to enhance quality.

3) Data: This category can be further subdivided as follows:

- Computer Assisted Instructions (CAI) use a device to provide lessons. The device can be referred to as a self-contained teaching machine.

- Computer Managed Instructions (CMI) mainly use a device to manage instructions and observe a student's progress.

- Computer Mediated Education (CME) consists of applications that ensure the delivery of materials.

The proposed Distance Education as a Service is basically a cloud-based framework that aims to fully incorporate the advantages and autonomy of cloud computing in the field of education. Its primary aim is to provide a pragmatic approach to education 
using current technology to educate more students where they live and work, see fig. 1.

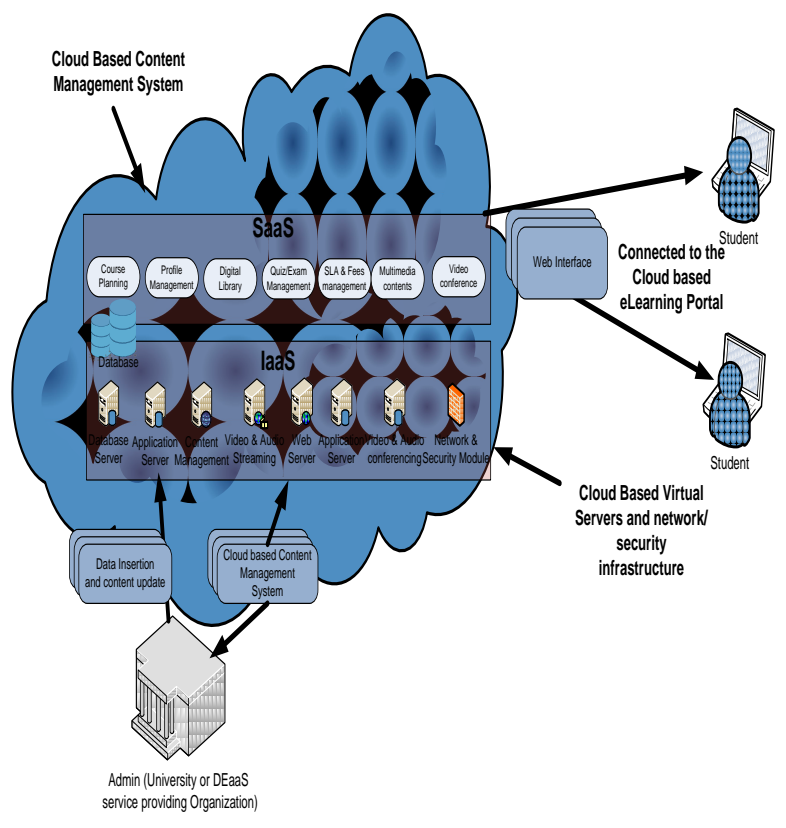

Figure 1. The proposed DEaaS Model

The implementation of DEaaS will be based on existing cloud service models i.e. Private Cloud, Public Cloud and Hybrid cloud. The model will provide a lucid and single interface for students to indulge their learning requirements with the latest technology in the industry at an affordable or very low price. It primarily will be implemented using SaaS and IaaS, which will also reduce the extra burden of managing the infrastructure on the institution and help students focus on core learning rather than on tasks of convoluted management.

The assumptions of the model follow:

- The framework for allocating resources is very exacting and complex.

- Most scholarly work and research will have to rely on open source frameworks and applications that are unrefined and limited.

- The Global campus concept is still in its infancy phase and most students do not have access to a library and are not able to work on their projects outside campus.

- There is a gap between industry and academia because shifts in the methodological shift within the education sector is not aligned with the technology shift in industry.

DEaaS is possible and would be an excellent solution for the problems stated above. This model consists of several components. One of the important components is the cloud service provider. It will serve as the provider of the infrastructure core, which will be the basis for implementation of the DEaaS. Public cloud service providers like Windows Azure or Amazon etc. are cheaper than implementing a new cloud. Moreover, the public cloud is accessible from any part of the world. But it can also be implemented in a private cloud like CloudStack or OpenStack. The choice will mainly depend on availability of resources and requirements of the institute. As already mentioned, this proposed model will work on both private and public clouds. If implemented in a public cloud, the Cloud service provider (CSP) will have an impact on this proposed model. CSPs provide flexible, scalable and robust computing services. They also provide a service framework for well-defined billing and efficient networking in addition to reliable and effective security frameworks for the resources provided by the cloud [19], all important features of the proposed model.

Various interactive resources will be part of the DEaaS system, which consists of two layers, a cloudbased content management system in SaaS and a cloud-based infrastructure in IaaS. The first layer includes a course planner, student profile management, digital library, quiz/exam management, multimedia content management, and video/voice conferencing tools. The second layer of the model, IaaS, includes the database server, web server, content management server, multimedia server, and network and security modules.

The student will have access to online courses through the web interfaces. Quality of Service (QoS) of the video/voice, network security, etc. will be managed by the network and security module. Whether for a single or multi-user profile, cloudbased technologies provide a highly interactive environment. This environment forms the basis for delivery of personalized and adapted-multimedia content. The advantage of a cloud-based architecture is the simplicity of working independently without using additional resources or software and without other problems with software installation and compatibility issues.

Its content management system will be used to provide an online classroom to students with facilities like online lectures and online assessments. It has the following characteristics:

- A portal for account management, which will manage and create various types of accounts for teachers, manager and students with access restrictions according to the type of account.

- A scalable and effective portal for course management, which offers a facility to manage and create course and related artifacts

- Assessment and quiz conducting functionality

A cloud-based portal will be used to collaborate between the content management system and the service provider. When a student raises a request for cloud services, facilitators have the ability to approve or reject it by using the cloud's management features. 
The portal will have the characteristics listed below:

- Easy access to the cloud through portal.

- Smooth interaction with the cloud service.

- The portal will keep track of the time period of services. Note that time tracking is applicable to the public cloud.

- The portal platform will be the single point of contact for raising requests to cloud services for students and facilitating managers of cloud to accept or reject it.

- The portal will have an interface for interacting with APIs of the service provider in order to enable access to cloud services.

- Managing and creating various types of accounts for teachers, manager and students with access restrictions according to the type of account.

- Facilitate course and related material creation and management.

- It will have assessment and quizzing functionality.

\subsection{Beneficiaries of Proposed Model}

Learning can be described as a process to acquire or modify knowledge, values and skills by studying. The target beneficiaries for DEaaS will be both students in K-16 as well as those in continuing education programs and those in rural areas that have traditionally been underserved. For underdeveloped and developing countries in particular, the DEaaS allows greater access to education in rural areas. These areas generally lack resources for accessing health care, transportation, communication and technology in addition to quality education. It is also observed that most of the students from rural areas quit study generally after completing secondary school [19]. Therefore, the DEaaS will directly address educational attrition and help developing countries improve their overall status.

The main goal of the model is to increase their ability to learn and to master the latest technology and applications as well as to increase their experience. Better education and better skills will help them get good jobs or help them to start their own businesses in such sectors as computer sales, network maintenance and design, software development or website development. This likewise will help them increase their income and raise the living standard of individuals and countries.

Still question may arise about how students in underdeveloped or developing countries will get cloud access. In recent years, the use of cellular Internet has increased significantly thereby increasing Internet accessibility from every corner of the world. Additionally, the Internet.org, an organization devoted to extending access to everyone, has recently begun offering affordable Internet access in many developing and underdeveloped countries.

\section{Conclusion}

The DEaaS model provides a framework for distance learning. Several applications and services will be integrated using this model to provide a seamless distance education service though the cloud. Personal profiles, interactive multimedia applications, video tutorials, video conferencing, voice conferencing, digital libraries, online quizzing etc. will be provided using this model. Students will have the flexibility to learn any subject by registering and attending e-classrooms. Students will have control over exercises and learn or review their work themselves at their own pace. Tests and quizzes will be provided to help students and their instructors evaluate student learning and gaps in that learning during and at the end of each course. Timely support from teachers will be available via voice or video conferencing when students face any problems. Online libraries or e-book directories will also be provided to allow students to access additional support and to extend their learning.

Every educational institution and most governments seek to provide opportunities to educate children who are deprived of the light of education. This proposed cloud-based distance education model will help schools and universities to move their distance education service toward the cloud, encouraging them to move from other softwarebased or physical infrastructure-based e-learning systems. The aim of this article is not only to provide guidelines to move toward cloud-based education. It also discusses how the proposed model could help underprivileged students across the world to enlighten themselves.

A cloud-based infrastructure is cheaper than a physical infrastructure. So a cloud-based model will decrease the cost of education and encourage educational organizations to provide a low cost distance education. Students of both rural and urban areas of poor and underdeveloped countries will have increased access to educational opportunities at a low cost. Future studies will focus on developing the model in specific sites and will extend the model's scope.

\section{References}

[1] Y. Jinxian and Z. Ying, "Advance your Education with Distance Learning," Education Technology and Training, ETT '09. Second International Conference on, Sanya, 2009, pp. 34-37.

[2] T. C. Simões, J. C. Rodrigues, J. F. Costa and M. L. Proença, "E-learning solutions for cloud environments," Cloud Computing and Communications (LATINCLOUD), IEEE Latin America Conference on, Porto Alegre, 2012, pp. 55-59. 
[3] M. J. Madar and O. Bin Ibrahim, "E-learning towards student academicperformance," in International Conference on Research and Innovation in Information Systems (ICRIIS), Kuala Lumpur, Malaysia, 2011, pp. 1-5.

[4] A. Al-Saai, A. Al-Kaabi, and S. Al-Muftah, "Effect of a Blended e-Learning Environment on Students' Achievement and Attitudes toward Using E-Learning in Teaching and Learning at the University Level," International Journal of Research in Education, vol. 29, 2011, pp. 34-55.

[5] W. He, D. Cernusca and M. Abdous,"Exploring Cloud Computing for Distance Learning Online", Journal of Distance Learning Administration, Volume XIV, Number III, Fall 2011.

[6] S. Rajam, R. Cortez, A. Vazhenin and S. Bahlal, "ELearning Computational Cloud (eLC2 ): Web Services Platform to Enhance Task Collaboration", 2010 IEEE/WIC/ACM International Conference on Web Intelligence and Intelligent Agent Technology, 2011, pp. 350-355.

[7] E. Kahiigi, L. Ekenberg, H. Hansson, F. Tusubira, and M. Danielson, "Exploring the e-Learning State of Art," Electronic Journal of e-Learning, vol. 6, 2008, pp. 77-88.

[8] S. Wu, C. Song, H. Chen, and J. Zhan, "E-learning Teaching Method Research and Ideas," in International Conference on Web Information Systems and Mining (WISM), Sanya, China, 2010, pp. 140-143.

[9] L. Xiao and Z. Wang, "Cloud Computing: A New Business Paradigmfor E-learning," in Third International Conference on Measuring Technology and Mechatronics Automation (ICMTMA),Shanghai, China, 2011, pp. 716719.

[10] S. Ouf, M. Nasr, and Y. Helmy, "An enhanced elearning ecosystem based on an integration between cloud computing and Web2.0," in IEEE International Symposium on Signal Processing and Information Technology (ISSPIT),Luxor, Egypt, 2010, pp. 48-55.

[11] D. Bo, Z. Qinghua, Y. Jie, L. Haifei, and Q. Mu, "An E-learning Ecosystem Based on Cloud Computing Infrastructure," in Ninth IEEE International Conference on Advanced Learning Technologies (ICALT), Riga, Latvia, 2009, pp. 125-127.

[12] M. Alabbadi, "Cloud computing for education and learning: Education and learning as a service (ELaaS)," Interactive Collaborative Learning (ICL), 2011 14th International Conference on, Piestany, 2011, pp. 589-594.

[13] B. Hayes, "Cloud computing," Communications of the ACM Web Sience, vol. 51, no. 7, 2008, pp. 9-11.

[14] G. Lin, D. Fu, J. Zhu, and G. Dasmalchi, "Cloud computing: IT as a Service," IT Professional, IEEE, vol. 11, no. 2, 2009, pp. 10-13.

[15] S. Hussain, Z. Wang and S. Rahim "E-learning Services for Rural Communities" International Journal of Computer Applications ,vol. 68, no. 5, 2013.
[16] C. Ciurea and P. Pocatilu, "Designing M-Learning Applications for Collaborative Virtual Environments", International Journal of Education and Information. Technologies, Issue 1, vol. 6, 2012, pp. 150-156.

[17] P. Pocatilu, F. Alecu, and M. Vetrici, "Using Cloud Computing for e-Learning Systems," in Recent Advances on Data Neworks, Communications, Computers, Academy of Economic Studies, ACM, Bucharest, Romania, 2009, pp. $54-59$.

[18] M. S. Fathi, M. Abedi, S. Rambat, S. Rawai, and M. Z. Zakiyudin "Context-aware cloud computing for construction collaboration," Journal of Cloud Computing, 2012, pp. 1-11.

[19] P. Tantatsanawong, A. Kawtrakul and W. Lertwipatraku, "Enabling Future Education with Smart Services", 2011 Annual SRII Global Conference, IEEE. 2011, pp. 550-556.

[20] T, Ercan, "Effective use of cloud computing in educational institutions", Procedia - Social and Behavioral Sciences, ELSIER, vol. 2, 2010, pp. 983-942.

[21] A. Fernandez, D. Peralta, F. Herrera and J. Benitez, "An Overview of E-Learning in Cloud Computing", Workshop on Learning Technology for Education in Cloud (LTEC'12), Springer. vol. 173, 2012, pp. 35-46.

[22] R. Kwan, R. Fox, F. Chan and P. Tsang (2008) 'Enhancing Learning Through Technology: Research on Emerging Technologies and Pedagogies', World Scientific Publishing. 